\title{
Tempol Alleviates Chronic Intermittent Hypoxia-Induced Pancreatic Injury Through Repressing Inflammation and Apoptosis
}

\author{
Yeying WANG ${ }^{1,2 *}$, Li AI $^{1 *}$, Bing HAI ${ }^{1}$, Yu CAO$^{1}, \operatorname{Ran~LI}^{1}$, Hui LI$^{1}$, Yongxia LI $^{1}$ \\ * These authors contributed equally to this work. \\ ${ }^{1}$ Department of Respiratory Medicine, The Second Affiliated Hospital of Kunming Medical \\ University, Kunming, Yunnan, People's Republic of China, ${ }^{2}$ Department of Epidemiology and \\ Biostatistics, School of Public Health, Kunming Medical University, Kunming, Yunnan, People's \\ Republic of China
}

Received August 27, 2018

Accepted January 14, 2019

\section{Summary}

Obstructive sleep apnea (OSA) has been demonstrated to be implicated in disorder of insulin secretion and diabetes mellitus. In this study, we aimed to evaluate the protective role of tempol, a powerful antioxidant, in chronic intermittent hypoxia (IH)-induced pancreatic injury. The rat model of OSA was established by IH exposure. The pathological changes, increased blood-glucose level, and raised proinsulin/insulin ratio in pancreatic tissues of rats received IH were effectively relieved by tempol delivery. In addition, the enhanced levels of pro-inflammatory cytokines, TNF-a, IL-1 $\beta$, IL-6, and inflammatory mediators, PGE2, cyclooxygenase-2 (COX-2), NO, and inducible nitric oxide synthase (iNOS) in pancreatic tissue were suppressed by tempol. Moreover, tempol inhibited IH-induced apoptosis in pancreatic tissue as evidenced by upregulated $\mathrm{Bcl}-2$ level, and downregulated Bax and cleaved caspase- 3 levels. Finally, the abnormal activation of mitogen-activated protein kinase (MAPK) and nuclear factor kappa-light-chain-enhancer of activated $B$ cells (NF-KB) signaling pathways induced by IH was restrained by tempol administration. In summary, our study demonstrates that tempol relieves IH-induced pancreatic injury by inhibiting inflammatory response and apoptosis, which provides theoretical basis for tempol as an effective treatment for OSA-induced pancreatic injury.

\section{Key words}

Tempol • Intermittent hypoxia • Pancreatic injury • Inflammation response • Apoptosis

\section{Corresponding author}

Y. Li, Department of Respiratory Medicine, The Second Affiliated Hospital of Kunming Medical University, 374 Dianmian Avenue, Kunming, Yunnan 650101, People's Republic of China. Fax: +86-871-65361017. E-mail: yxli5323@sina.com

\section{Introduction}

Obstructive sleep apnea (OSA), characterized by recurrent apnea, sleep fragmentations, and daytime sleepiness, is a rather common chronic sleep disorder (Punjabi 2008). Long-term untreated OSA may result in multiple health impairments, such as kidney injury (Abuyassin et al. 2018), cardiovascular disease (Walia et al. 2014), lung damage (Braun et al. 2017), metabolic disorders (Drager et al. 2013), which compromises the quality of life, reduces productivity, and brings psychological and economic burdens to patients.

It has been reported that OSA significantly correlates with high-risk of incident diabetes (Nagayoshi et al. 2016). Our previous results suggested that OSA could lead to insulin secretion disorder and pancreatic injury in rats exposure to chronic intermittent hypoxia (IH) rats (Wang et al. 2017). Moreover, IH promotes the production of large amounts of reactive oxygen species (ROS), which results in insulin resistance and glucose intolerance (Clarenbach et al. 2011). Although the detailed pathogenesis of OSA-induced pancreatic injury is not well understood, oxidative stress may participate in the pathogenic mechanisms. For now, antioxidant therapy 
has been confirmed to be effective for treating OSA (Sadasivam et al. 2011). This may provide clues to searching potential therapeutic measures for OSA-induced pancreatic injury.

Tempol (4-hydroxy-2,2,6,6-tetramethylpiperidine- $N$-oxyl) is a soluble superoxide dismutase (SOD) mimetic agent. Tempol is a powerful anti-oxidant and contributes to mopping up ROS in a variety models of oxidative stress (Wilcox 2010). Tempol suppressed IH-induced myocardial infarction aggravation (Ramond et al. 2013), sustained elevation of blood pressure (Khan et al. 2011), pharyngeal dilator muscle dysfunction (Skelly et al. 2012), and so on. Previous studies also suggested that tempol protected against pancreatic damage in pancreatitis rat model (Erbis et al. 2015, Marciniak et al. 2016). In addition, tempol treatment could protect pancreatic beta cells via inhibiting fibrosis and apoptosis in type 2 diabetes rats (Lee et al. 2011). However, the role of tempol in IH-induced pancreatic injury has not been determined.

In the present study, the rats were subjected to IH to simulate the OSA model in vivo. The beneficial effect of tempol on IH-induced pancreatic injury and its related mechanisms were elucidated.

\section{Materials and Methods}

\section{Animal model}

Twenty-four Wistar rats (body weight range of 200-220 g) were obtained from HFK Bioscience Co., LTD (Beijing, China) and randomly divided into four experimental groups: i) normal air (NA) group, ii) chronic intermittent hypoxia (IH) group, iii) $\mathrm{IH}+$ tempol group, iv) NA+tempol group. To determine the protective effects of tempol in IH-induced pancreatic injury, the rats in iii) \& iv) groups were received equal-volume freshly prepared drinking water containing $1 \mathrm{mM}$ tempol during receiving $\mathrm{IH}$ or NA every day. The rats in the other groups drank equal-volume tap water. The rats in IH group were persistently exposed to $5 \% \quad \mathrm{O}_{2}$ $(60 \mathrm{~s}) / 21 \% \mathrm{O}_{2}(60 \mathrm{~s})$ cycles in a controlled chamber every day from 9:00 to 5:00 pm for 12 weeks. The rats of NA groups were subjected to air always containing $21 \%$ $\mathrm{O}_{2}$. Twelve weeks after the treatment, the rats were anesthetized by pentobarbital sodium $(50 \mathrm{mg} / \mathrm{kg}$, intraperitoneal injection) and sacrificed. The arterial blood and pancreatic tissues were collected for further tests. All animal experimental procedures were approved by the Institutional Animal Care and Use Committees of
The Second Affiliated Hospital of Kunming Medical University.

\section{Hematoxylin-eosin (HE) staining}

The pancreatic tissues of rats were fixed in $4 \%$ formaldehyde, embedded in paraffin and then cut into $5-\mu \mathrm{m}$ sections for routine HE staining. The morphologic alterations were observed under a light microscopy.

Detection of insulin, proinsulin content and blood glucose level

The insulin or proinsulin content in pancreatic tissues was assessed by Chemiluminescent Immunoassay Kit For Insulin (USCN, China) or commercially-available ELISA Kit for proinsulin (WHB, China), and the blood glucose level was detected by the Glucose Assay Kit (Nanjing Jiancheng Bioengineering Institute, China), following the manufacturer's instructions.

Detection of pro-inflammatory cytokines TNF- $\alpha, I L-1 \beta$ and IL-6

The levels of TNF- $\alpha$, IL- $1 \beta$, and IL- 6 in the pancreatic tissues were assessed by commerciallyavailable ELISA kits (Boster, China), according to the manufacturer's instructions.

\section{Detection of NO and PGE2 content}

The content of NO or PGE2 in pancreatic tissues were determined by Nitric Oxide (NO) assay kit (Nanjing Jiancheng Bioengineering Institute) or Prostaglandin E2 (PGE2) ELISA Kit (USCN), following the manufacturer's instructions.

\section{Western blot}

Proteins were extracted from the pancreatic tissues by RIPA lysis buffer (Beyotime, China) containing $1 \%$ PMSF (Beyotime). Protein concentration in each sample was quantified by an Enhanced BCA Protein Assay Kit (Beyotime). Protein samples with equal amount $(40 \mu \mathrm{g})$ were subjected to a SDS-PAGE gel and then transferred onto polyvinylidene difluoride membranes (Millipore, USA). Then the membranes were blocked with $5 \%$ skim milk for $1 \mathrm{~h}$ at room temperature, incubated with primary antibodies against COX-2 (1:700, Proteintech, USA), iNOS (1:500, Proteintech, USA), $\mathrm{I} \kappa \mathrm{B} \alpha(1: 1,000$, Cell Signaling Technology, USA), $\mathrm{p}-\mathrm{I} \kappa \mathrm{B} \alpha$ (1:1,000, Cell Signaling Technology, USA), NF-кB (1:1,000, Proteintech, USA), Bax (1:1,000, Proteintech, USA), Bcl-2 (1:700, Abcam, UK), cleaved caspase-3 
(1:1,000, Cell Signaling Technology, USA), ERK (1:1,000, Cell Signaling Technology, USA), p-ERK (1:2,000, Cell Signaling Technology, USA), JNK (1:1,000, Cell Signaling Technology, USA), p-JNK (1:1,000, Cell Signaling Technology, USA), P38 (1:1,000, Cell Signaling Technology, USA), p-P38 (1:1,000, Cell Signaling Technology, USA), GAPDH (1:5,000, Bioss, China) and Histone H3 (1:1,000, Proteintech, USA) at $4{ }^{\circ} \mathrm{C}$ overnight, and then with corresponding secondary antibody at $37^{\circ} \mathrm{C}$ for $45 \mathrm{~min}$. The bands were visualized and detected by BeyoECL Plus reagent (Beyotime). The grayscale values of the bands were analyzed by Gel-Pro-Analyze software.

Terminal deoxynucleotidyl transferase dUTP nick end labeling (TUNEL)

The apoptosis in pancreatic tissues was determined by the In Situ Cell Death Detection Kit (Roche, Switzerland), according to the manufacturer's instructions. In short, the fixed pancreatic tissues were embedded in paraffin and cut into $5-\mu \mathrm{m}$ thick sections. Then, the sections were incubated with $0.1 \%$ Triton $\mathrm{X}-100$, blocked with $3 \% \mathrm{H}_{2} \mathrm{O}_{2}$. After washing with PBS for three times, the sections were incubated with TUNEL reaction mixture at $37^{\circ} \mathrm{C}$ for $60 \mathrm{~min}$. Thereafter, the sections were counter stained with hematoxylin, observed and photographed by a light microscopy at a magnification of $400 \times$.

\section{Electrophoretic mobility shift assay (EMSA)}

The nuclear proteins were extracted from the pancreatic tissues using a Nuclear Protein Extraction Kit (Beyotime) and quantified by an Enhanced BCA Protein Assay Kit (Beyotime). A commercial EMSA kit (Viagene, China) was used to determine the DNA binding activity of NF- $\mathrm{BB}$ in pancreatic tissues. Briefly, equal amount of nuclear protein $(25 \mu \mathrm{g})$ was reacted with $0.5 \mu \mathrm{l}$ biotin end-labelled probe for $20 \mathrm{~min}$ at room temperature, separated on a $6.5 \%$ polyacrylamide gel, electronically transferred onto nylon membrane. After cross-linked under the excitation of UV light for $30 \mathrm{~min}$, the results were visualized by chemiluminescence.

\section{Statistical analysis}

The GraphPad Prism 5 software was used to perform statistical analysis, and experimental data were presented as mean \pm standard deviation (SD). One-way analysis of variance (ANOVA) followed by Bonferroni's Multiple Comparison Test was used to evaluate significant differences among multiple groups. P value less than 0.05 was considered to have a significant statistical difference.

\section{Results}

\section{Effect of tempol on IH-induced pancreatic tissue injury}

First, we observed the pathological changes in pancreatic tissues using HE staining assay. As shown in Figure 1A, IH exposure resulted in obvious damage in pancreatic cells with shrinked nuclei and faded cytoplasm staining. However, administration of tempol significantly alleviated the above pathological changes in pancreatic tissues. In addition, the blood glucose level was obviously increased in IH group, which could be adjusted to the normal level by tempol treatment (Fig. 1B). Furthermore, IH exposure led to distinct decrease in insulin content, while evident increases in proinsulin content and proinsulin/insulin ratio in pancreatic tissue, as compared with NA group. Whereas, tempol administration could effectively reverse the changes in insulin, proinsulin, and proinsulin/insulin ratio induced by IH (Fig. 1C-E).

Effect of tempol on IH-induced inflammatory response in pancreatic tissue

As shown in Figure $2 \mathrm{~A}-\mathrm{C}$, the levels of pro-inflammatory cytokines TNF- $\alpha$, IL-6, and IL-1 $\beta$ in pancreatic tissue were remarkably enhanced by IH exposure, which were significantly restrained by delivery of tempol. Moreover, the inflammatory mediators PGE2 and NO levels in pancreatic tissue were determined. As presented in Figure 2D-E, administration of tempol significantly suppressed $\mathrm{IH}$-induced increase in levels of PGE2 and NO in pancreatic tissue. The protein levels of COX-2 and iNOS in pancreatic tissue were upregulated by IH exposure, whereas tempol delivery obviously decreased the COX-2 and iNOS levels (Fig. 2F-H).

\section{Effect of tempol on IH-induced apoptosis in pancreatic} tissue

The apoptosis in pancreatic tissue was evaluated by TUNEL staining and showed in Figure $3 \mathrm{~A}$. There were evident more apoptotic cells in the pancreatic tissue, as evidenced by strong brown staining in the nuclei after treatment with IH. However, administration of tempol could significantly suppress IH-induced apoptosis. In addition, the levels of a series of apoptosis-related 
proteins were detected by western blot. As illustrated in Figure 3B-E, IH exposure caused decreased level of Bcl-2, while increased levels of Bax and cleaved caspase-3 in the pancreatic tissue, whereas tempol administration effectively inhibited the level changes in above proteins.

A NA $\mathrm{IH}$ IH+tempol $\mathrm{NA}+$ tempol

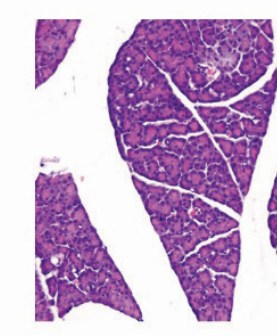

B

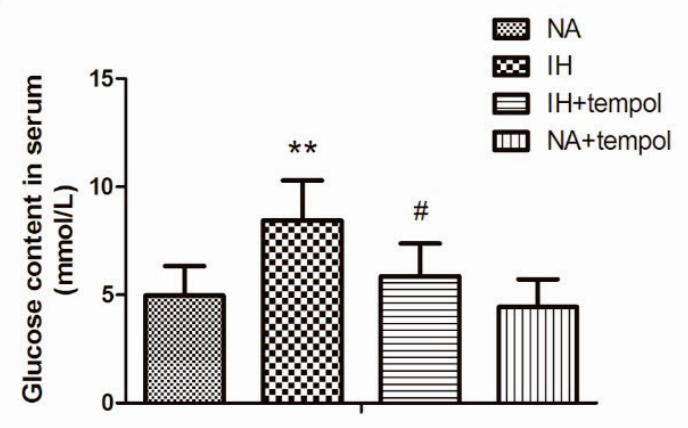

D

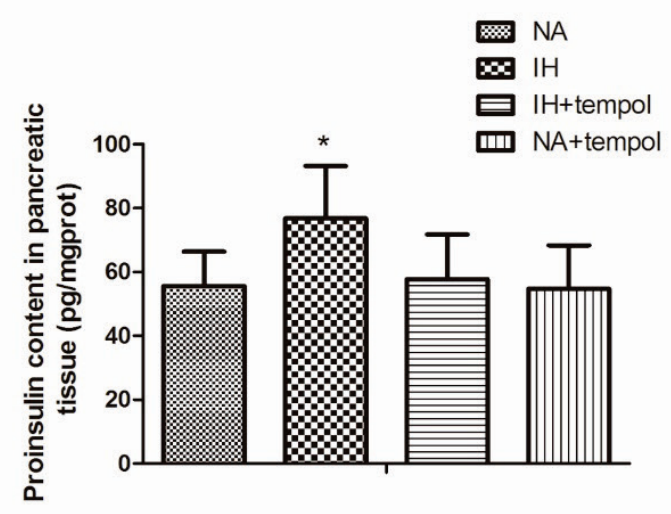

C
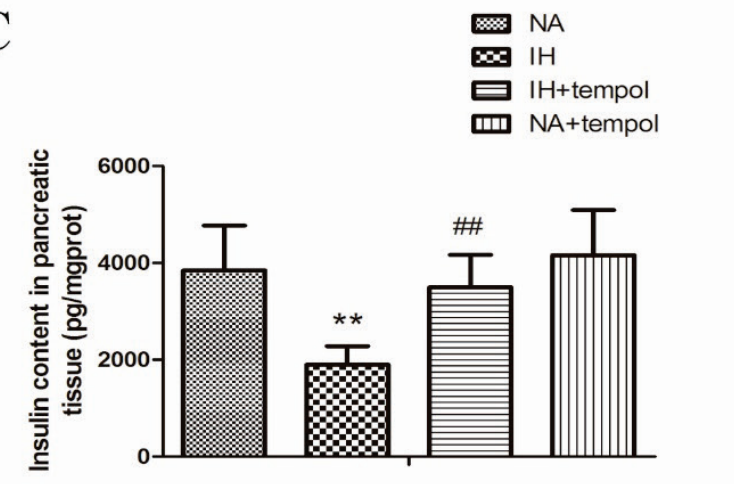

E

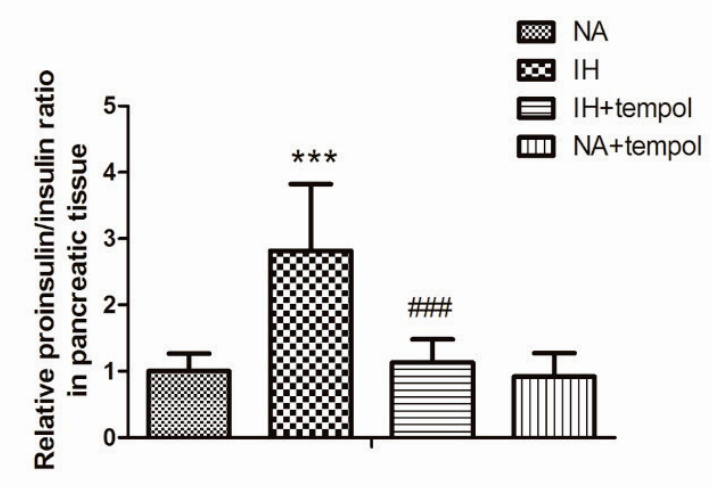

Fig. 1. Tempol relieved IH-induced pancreatic tissue injury. (A) Pathological changes of pancreatic tissue were evaluated by HE staining. (B) Blood glucose level of the rats was detected. The insulin (C) and proinsulin (D) levels in pancreatic tissue were assessed by ELISA. (E) The proinsulin/insulin ratio was calculated and shown. The experimental data were expressed as mean \pm SD $(n=6) .{ }^{* *} \mathrm{P}<0.01, * * * \mathrm{P}<0.001$ vs. NA. ${ }^{\#} \mathrm{P}<0.05,{ }^{\# \#} \mathrm{P}<0.01,{ }^{\# \# \#} \mathrm{P}<0.001$ vs. IH.

Effect of tempol on the activation of MAPK signaling pathway

Our previous study has demonstrated that MAPK signaling pathway participated in IH-induced pancreatic injury. So we further evaluated whether tempol regulated $\mathrm{IH}$-induced activation of the MAPK pathway. As presented in Figure 4A-D, tempol delivery significantly restrained $\mathrm{IH}$-induced increase in levels of p-ERK, p-JNK, and p-P38 in pancreatic injury. These results indicated that inhibition of the MAPK signaling pathway activation was involved in the beneficial effect of tempol against IH-induced pancreatic injury.

Effect of tempol on the activation of $N F-\kappa B$ signaling pathway

$\mathrm{NF}-\kappa \mathrm{B}$ signaling pathway has been confirmed to play crucial roles in inflammatory response. So we further investigated the role of tempol in NF- $\kappa$ B signaling pathway. As shown in Figure 5A-D, the protein levels of $\mathrm{p}-\mathrm{I} \kappa \mathrm{B} \alpha$, nuclear $\mathrm{NF}-\kappa \mathrm{B}$ were increased, while the $\mathrm{I} \kappa \mathrm{B} \alpha$ 
and cytoplasmic NF- $\kappa \mathrm{B}$ levels were decreased in the pancreatic tissue after exposure to $\mathrm{IH}$, which could be obviously restrained by tempol. Moreover, IH-induced enhanced DNA binding activity of NF- $\kappa$ B was evidently inhibited by the administration of tempol (Fig. 5E-F).

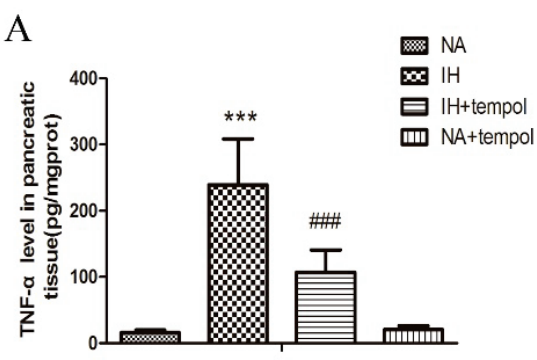

$\mathrm{D}$
B

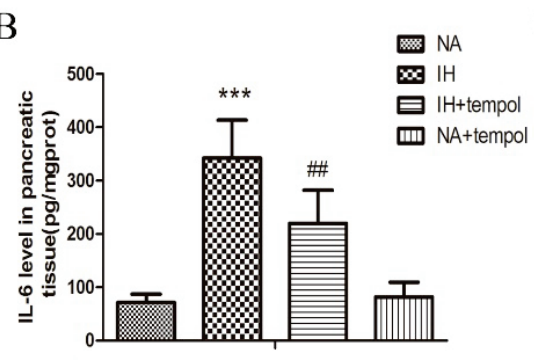

$\mathrm{E}$
$\mathrm{C}$

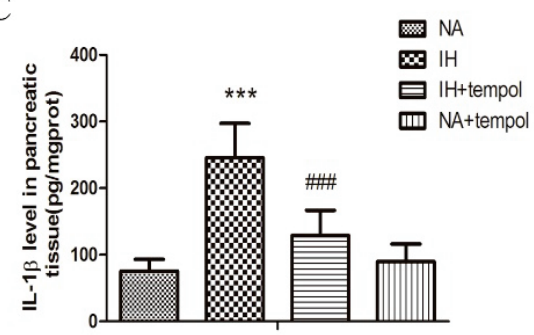

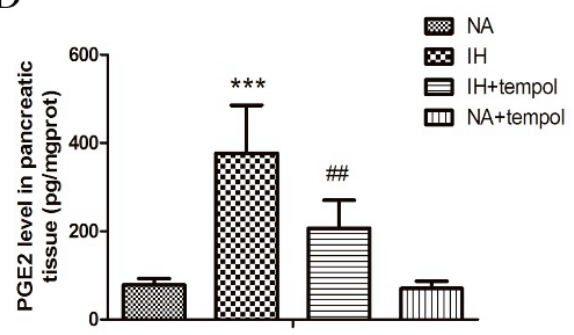

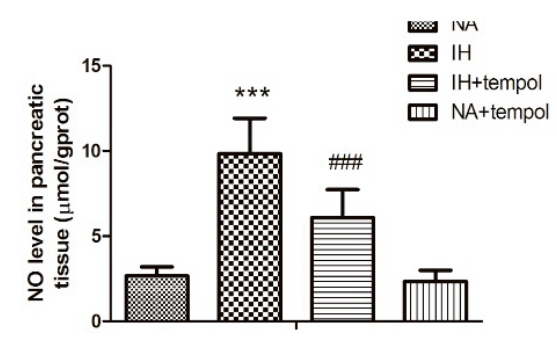

$\mathrm{F}$

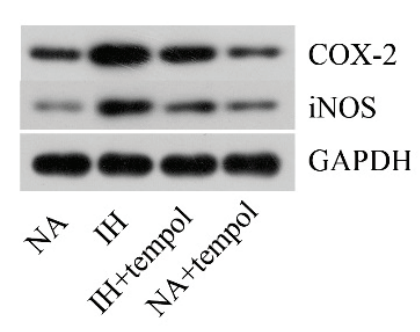

G

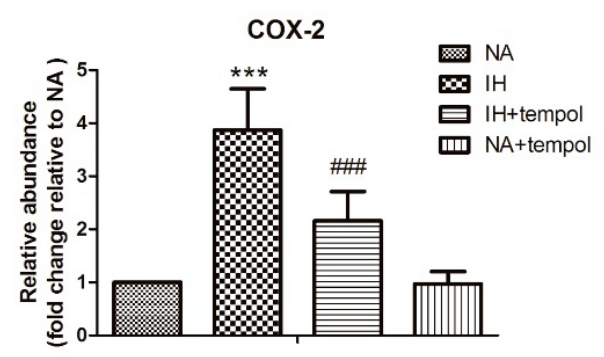

$\mathrm{H}$

Fig. 2. Tempol repressed IH-induced inflammatory response in pancreatic tissue of the rats. The levels of TNF-a (A), IL-6 (B), IL-1ß (C), and PGE2 (D) in pancreatic tissues were determined by ELISA. (E) The level of NO in pancreatic tissues was detected by commercial kit. (F) The protein levels of COX-2 and iNOS were assessed by western blot assay. GAPDH was used as a loading control. (G-H) Quantitative analysis of the grayscale value of the protein bands. The experimental data were expressed as mean \pm SD $(n=6)$. ** $\mathrm{P}<0.01, * * * \mathrm{P}<0.001$ vs. NA. ${ }^{\# \#} \mathrm{P}<0.01,{ }^{\# \# \#} \mathrm{P}<0.001$ vs. IH.

\section{Discussion}

This is the first study that investigates the beneficial roles of tempol in pancreatic injury in a rat model of IH. Our results showed that tempol administration relieved $\mathrm{IH}$-induced pathological changes in pancreatic tissue, elevated blood glucose, raised proinsulin/insulin ratio, inflammatory response, apoptosis, and abnormal activation of MAPK and NF- $\kappa$ B signaling pathways.

Previous studies have demonstrated that IH may lead to impaired pancreatic $\beta$-cell function, which provides evidence for OSA patients with high risk of diabetes (Wang et al. 2013). Our previous results also suggested that IH caused dysfunction of pancreas and insulin secretion disorder. The pancreatic trauma may further intensify the disturbance of lipid metabolism, which contributes to the course of obesity, diabetes mellitus and cardiovascular diseases. So seeking effective intervening measures to protect against IH-induced pancreatic injury has important clinical significance. In this study, we focused on the protective effect of tempol, a powerful antioxidant. As we expected, our results indicated that tempol effectively alleviated $\mathrm{IH}$-induced pancreatic injury, and improved pancreas function as evidenced by adjusting blood glucose, pancreatic insulin and proinsulin to normal levels. 
A

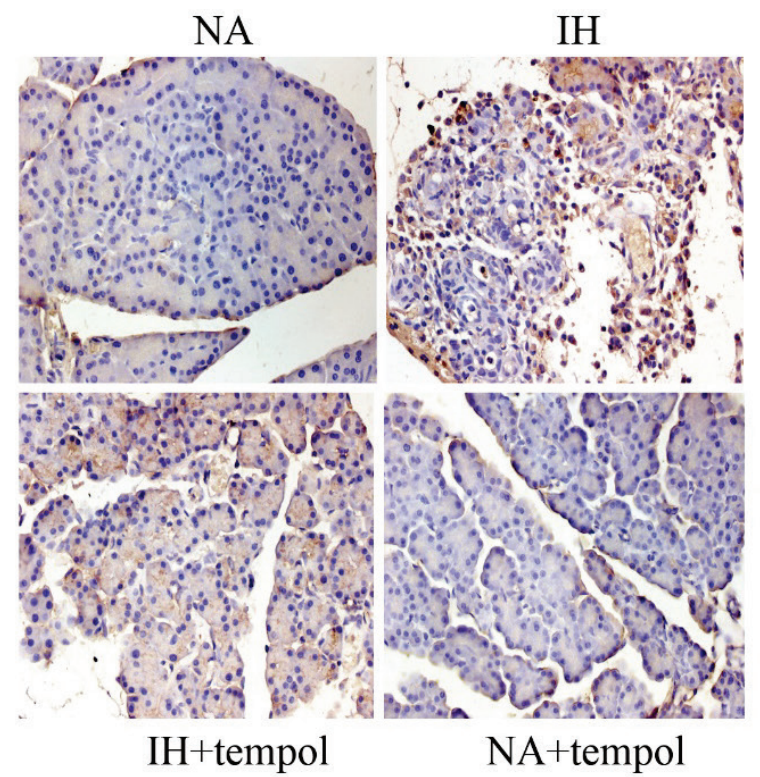

B

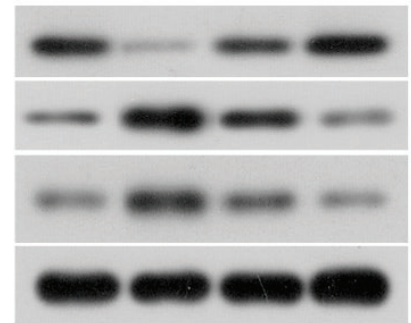

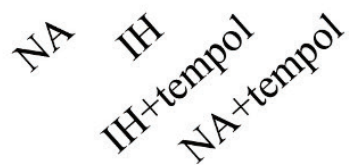

Bcl-2

Bax

cleaved caspase-3

\section{GAPDH}

D

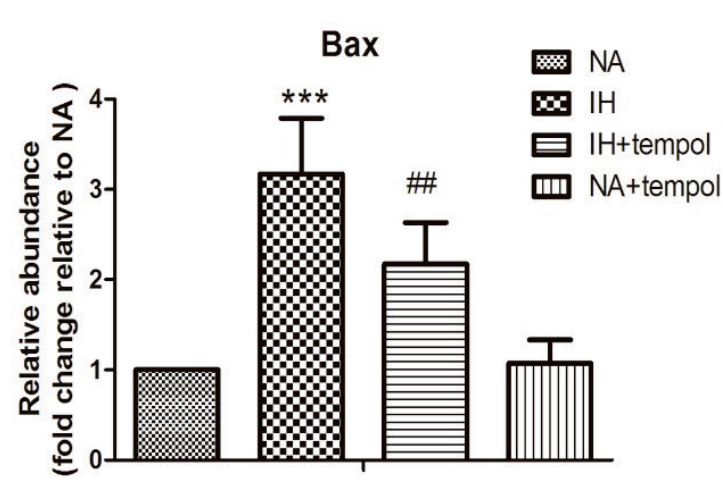

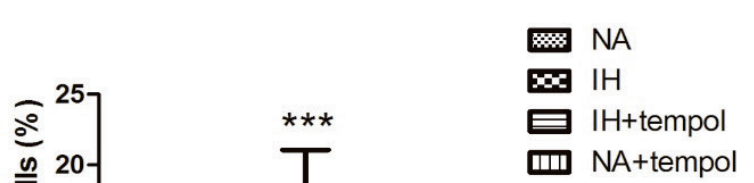

C
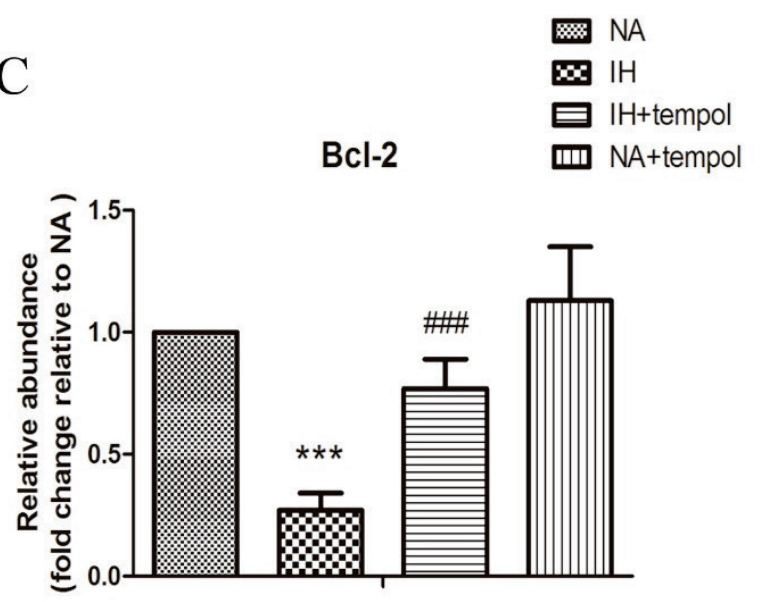

E

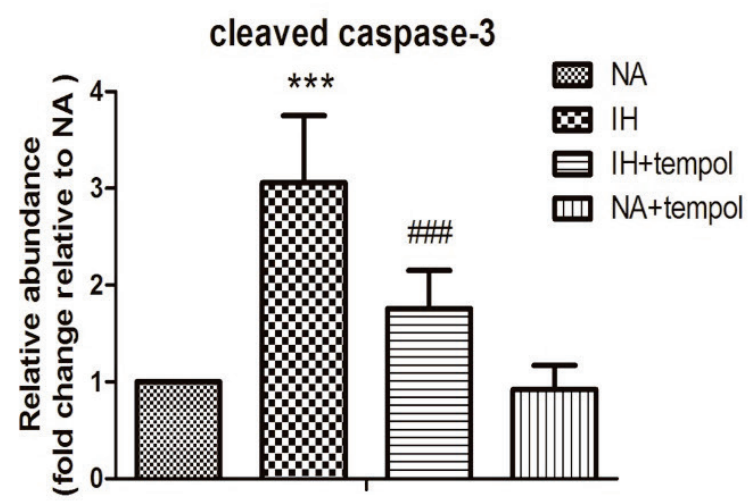

Fig. 3. Tempol restrained IH-induced apoptosis in pancreatic tissue. (A) TUNEL staining was performed to evaluate the apoptosis in pancreatic tissue. (B) The protein levels of Bcl-2, Bax, and cleaved caspase-3 in pancreatic tissue were detected by western blot assay. (C-E) Quantitative analysis of the grayscale value of the protein bands. The experimental data were expressed as mean $\pm S D(n=6)$. *** $\mathrm{P}<0.001$ vs. NA. ${ }^{\# \#} \mathrm{P}<0.01,{ }^{\# \# \#} \mathrm{P}<0.001$ vs. IH.

Inflammatory response has been demonstrated to participate in IH-induced pancreatic injury, and the levels of pro-inflammatory cytokines, TNF- $\alpha$, IL-6, and IL- $1 \beta$, have been shown to be enhanced by IH (Wang et al.
2017). According to the present study, tempol delivery significantly downregulated the increased levels of TNF- $\alpha$, IL- 6 , and IL-1 $\beta$ in pancreatic tissue induced by IH exposure. During inflammation, a series of 
inflammatory mediators, such as NO and PGE2, are excessively released and further amplify the inflammation. NO is produced by iNOS-catalyzed oxidation of L-arginine. Similarly, the biosynthesis of PGE2 is catalyzed by COX-2. In normal physiological conditions, the inflammatory mediators, iNOS and COX-2, are present at low levels (Kolyada et al. 1996, Sudbo et al. 2003). While in inflammation, these two enzymes are overproduced and cause cell and tissue damage (Choy et al. 2008). Therefore, inhibiting the levels of iNOS and COX-2, and their catalyzed production of NO and PGE2 would be effective means for restraining inflammation. In this study, the increased levels of NO and PGE2, and upregulated protein levels of iNOS and COX-2 in pancreatic tissue of rats after exposure to IH were strikingly suppressed by tempol treatment, suggesting that tempol restrained $\mathrm{IH}$-induced inflammatory response in pancreatic tissue.
A

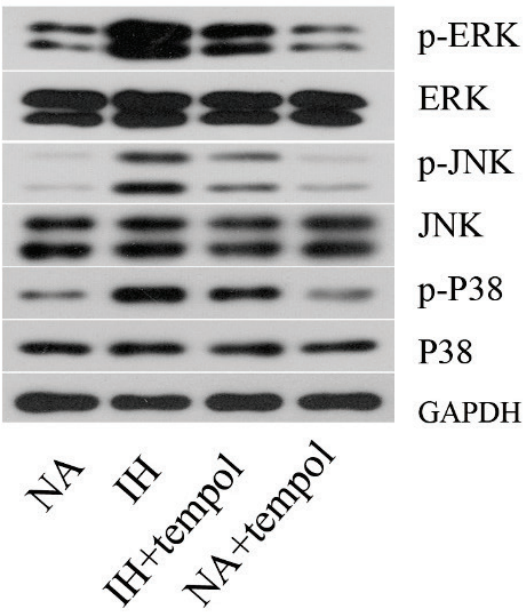

C

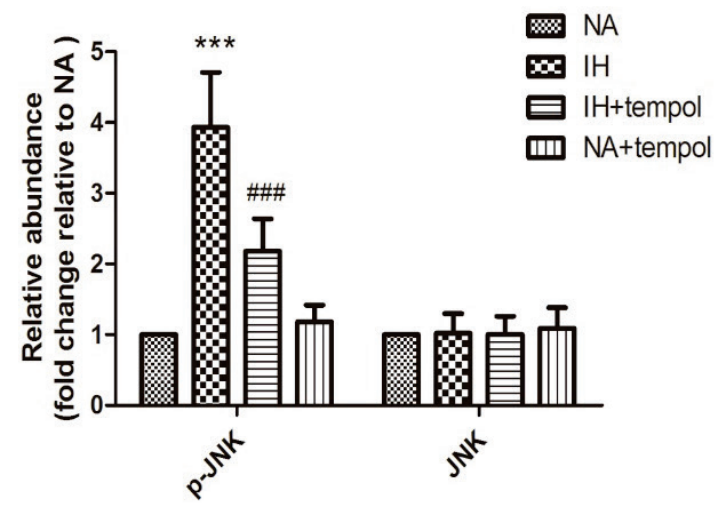

B

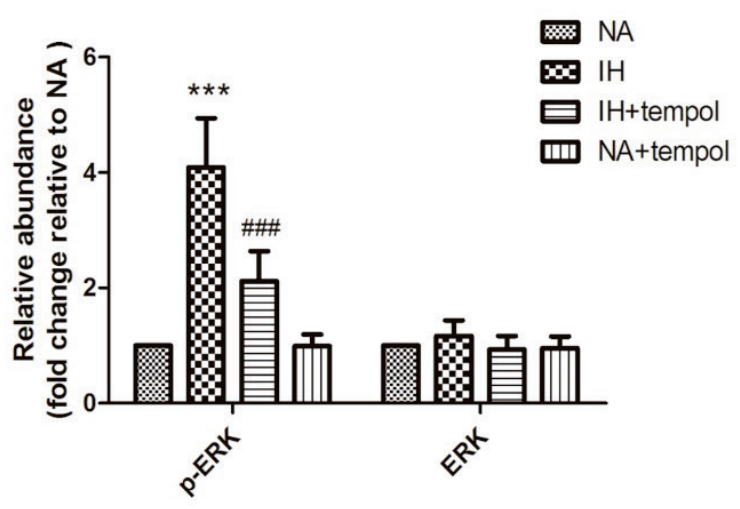

D

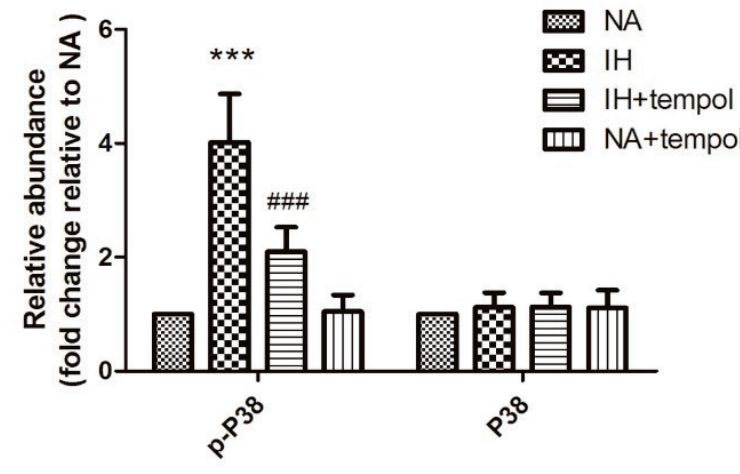

Fig. 4. Tempol inhibited IH-induced activation of MAPK signaling pathway. (A) The protein levels of p-ERK, ERK, p-JNK, JNK, p-P38, and P38 in pancreatic tissue were evaluated by western blot assay. (B-D) Quantitative analysis of the grayscale value of the protein bands. The experimental data were expressed as mean $\pm \mathrm{SD}(\mathrm{n}=6)$. $* * * P<0.001$ vs. NA. ${ }^{\# \# \# ~} \mathrm{P}<0.001$ vs. IH.

Apoptosis has been confirmed to be involved in the underlying mechanisms of $\mathrm{IH}$-induced pancreatic $\beta$-cell death (Yokoe et al. 2008, Xu et al. 2009, Fang et al. 2014). These studies suggested that apoptosis was one of important consequences of IH exposure. Thus, suppressing apoptosis may effectively relieve pancreatic injury induced by $\mathrm{IH}$. Our results were as expected and showed that tempol treatment obviously inhibited apoptosis in pancreatic tissue after exposure to IH.
Moreover, the detailed mechanisms that regulated apoptosis by tempol were investigated. Apoptosis is a programmed process regulated by multiple signal transduction pathways. Apoptosis is typical of activation of caspase cascades. A research by Zheng et al. (2012) indicated that caspase- 3 activation was occurred in mouse insulinemia cell line 6 that suffered apoptosis following exposure to hypoxia. It is well acknowledged that Bcl-2 family proteins implicate in the regulation of apoptosis 
(Hardwick and Youle 2009). Bcl-2 is a well-known anti-apoptotic protein, while Bax is a pro-apoptotic protein of Bcl-2 family. Research also demonstrated that chronic IH resulted in $\beta$-cell apoptosis by downregulating Bcl-2 and upregulating Bax (Fang et al. 2014). According to our results, tempol administration restrained
IH-induced upregulation of Bax and cleaved caspase- 3 and downregulation of Bcl-2 in pancreatic tissue. These results suggested that inhibiting apoptosis was involved in the beneficial effect of tempol against IH-induced pancreatic injury.
A

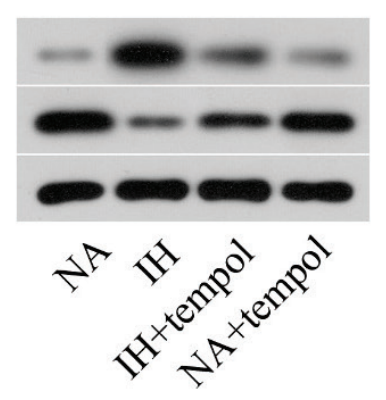

C
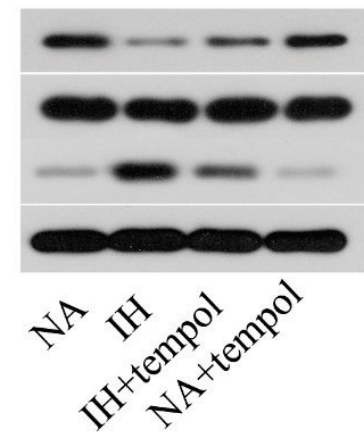

E

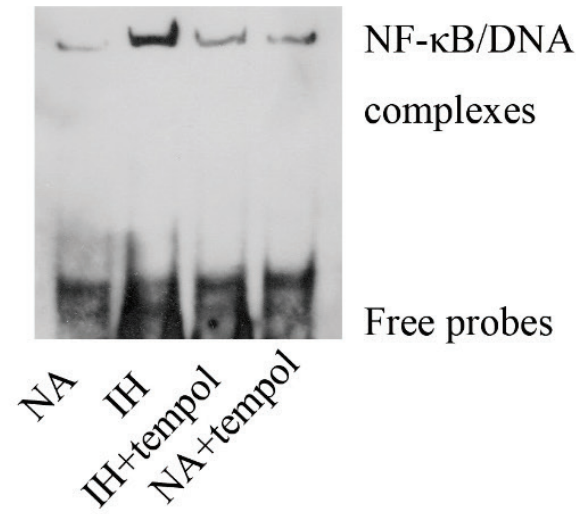
$\mathrm{p}-\mathrm{I} \kappa \mathrm{B} \alpha$
IкB $\alpha$
GAPDH GAPDH Histone $\mathrm{H} 3$
B NF- $\kappa B$ nucleus

D

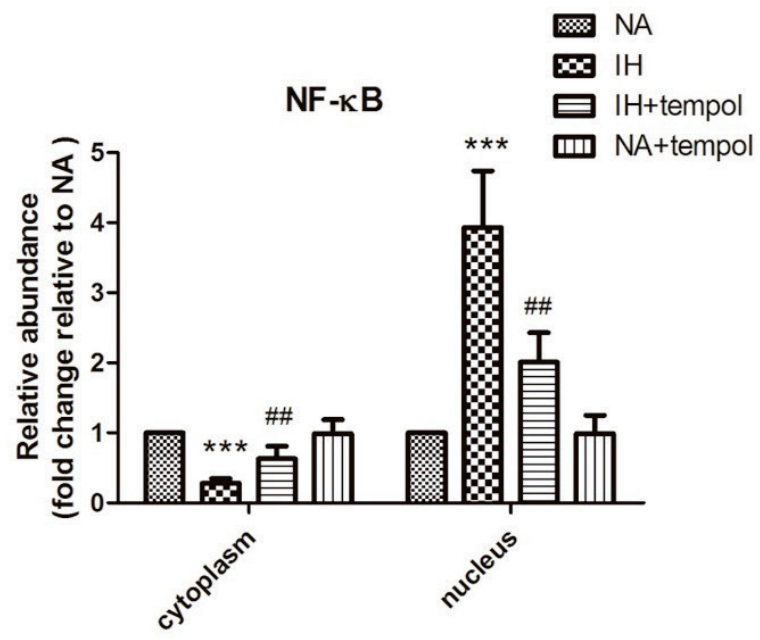

F

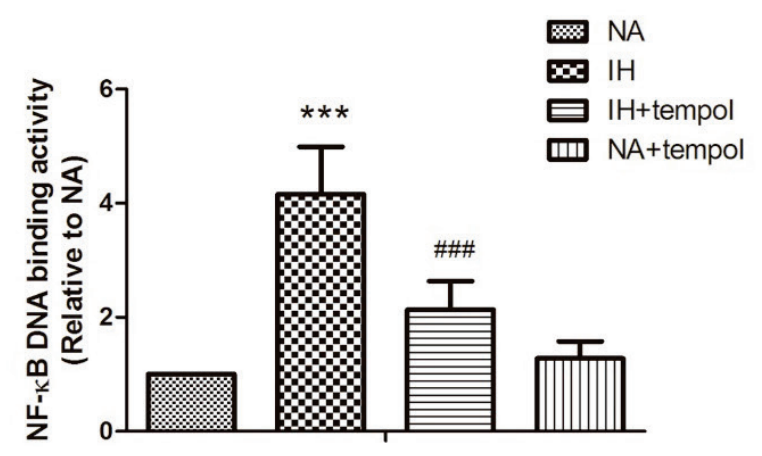

Fig. 5. Tempol suppressed IH-induced activation of NF-kB signaling pathway. The protein level of p-IkBa and IkBa (A), cytoplasmic NF-KB and nuclear NF-KB (C) in pancreatic tissue were assessed by western blot assay. (B, D) Quantitative analysis of the grayscale value of the protein bands. (E) EMSA was performed to assess the DNA binging activity of NF-KB in pancreatic tissue. (F) Quantitative analysis of the DNA binging activity. The experimental data were expressed as mean $\pm S D(n=6)$. *** $P<0.001$ vs. NA. \#\# $P<0.01$, \#\#\# $\mathrm{P}<0.001$ vs. IH. 
MAPK and NF- $\mathrm{BB}$ signaling pathways are confirmed to play crucial roles in inflammatory response (Chen et al. 2018, Gao et al. 2018). Suppressing the abnormal activation of MAPK and NF- $\kappa$ B pathways has been reported to attenuate $\mathrm{IH}$-induced inflammation (Kang et al. 2017, Liu et al. 2017). Moreover, MAPK activation has also participated in $\mathrm{IH}$-induced apoptosis (Wu et al. 2016). There are three members, including ERK, JNK, and P38, in MAPK family. Upon stimulation, these members are phosphorylated and then regulate downstream signaling events. Zhao et al. (2016) and our previous results indicated that ERK, JNK, and P38 were activated after exposure to IH. In this study, IH-induced hyperphosphorylation of ERK, JNK, and P38 in pancreatic tissue was restrained by tempol treatment. It is suggested that $\mathrm{NF}-\kappa \mathrm{B}-$ mediated inflammatory response is affected by p38 MAPK (Kumar et al. 2003). NF- $\kappa \mathrm{B}$ is inactivated in cytoplasm by binding to $\mathrm{I} \kappa \mathrm{B} \alpha$ under normal conditions. Whereas, $\mathrm{I} \kappa \mathrm{B} \alpha$ is phosphorylated and degraded under inflammatory conditions, which promotes the translocation of $\mathrm{NF}-\kappa \mathrm{B}$ from cytoplasm to nucleus and the subsequent activation of proinflammatory molecules (Fang et al. 2007, Dai et al. 2011). Our results showed that the nuclear translocation and activation of $\mathrm{NF}-\kappa \mathrm{B}$ in pancreatic tissue after exposure to IH were significantly repressed by tempol. From these results, we suggested that MAPK and NF- $\kappa \mathrm{B}$ pathways were involved in the regulatory mechanisms of tempol in $\mathrm{IH}$-induced pancreatic injury.

Taken together, our study demonstrated the beneficial effect of tempol on hampering IH-induced pancreatic injury that could lead to dysfunction of pancreatic $\beta$-cell and promote the progression of diabetes. Therefore, tempol may be a potential treatment for OSA patients with pancreatic injury.

\section{Conflict of Interest}

There is no conflict of interest.

\section{Acknowledgements}

This study was supported by a grant from the National Natural Science Foundation of China (No. 81460017).

\section{References}

ABUYASSIN B, BADRAN M, AYAS NT, LAHER I: Intermittent hypoxia causes histological kidney damage and increases growth factor expression in a mouse model of obstructive sleep apnea. PLoS One 13: e0192084, 2018.

BRAUN RK, BROYTMAN O, BRAUN FM, BRINKMAN JA, CLITHERO A, MODI D, PEGELOW DF, ELDRIDGE M, TEODORESCU M: Chronic intermittent hypoxia worsens bleomycin-induced lung fibrosis in rats. Respir Physiol Neurobiol 256: 97-108, 2017.

CHEN X, HAN R, HAO P, WANG L, LIU M, JIN M, KONG D, LI X: Nepetin inhibits IL-1beta induced inflammation via NF-kappaB and MAPKs signaling pathways in ARPE-19 cells. Biomed Pharmacother 101: 87-93, 2018.

CHOY CS, HU CM, CHIU WT, LAM CS, TING Y, TSAI SH, WANG TC: Suppression of lipopolysaccharide-induced of inducible nitric oxide synthase and cyclooxygenase-2 by Sanguis Draconis, a dragon's blood resin, in RAW 264.7 cells. J Ethnopharmacol 115: 455-462, 2008.

CLARENBACH CF, WEST SD, KOHLER M: Is obstructive sleep apnea a risk factor for diabetes? Discov Med 12: 17-24, 2011.

DAI JN, ZONG Y, ZHONG LM, LI YM, ZHANG W, BIAN LG, AI QL, LIU YD, SUN J, LU D: Gastrodin inhibits expression of inducible NO synthase, cyclooxygenase-2 and proinflammatory cytokines in cultured LPS-stimulated microglia via MAPK pathways. PLoS One 6: e21891, 2011.

DRAGER LF, TOGEIRO SM, POLOTSKY VY, LORENZI-FILHO G: Obstructive sleep apnea: a cardiometabolic risk in obesity and the metabolic syndrome. J Am Coll Cardiol 62: 569-76, 2013.

ERBIS H, AYKOTA MR, OZTURK B, KABAY B, SUNGURTEKIN U, OZDEN A, YENISEY C, TURK NS, ERDEM E: Effects of tempol on experimental acute necrotizing pancreatitis model in rats. J Invest Surg $\mathbf{2 8}$ : 268-275, 2015.

FANG IM, YANG CH, YANG CM, CHEN MS: Linoleic acid-induced expression of inducible nitric oxide synthase and cyclooxygenase II via p42/44 mitogen-activated protein kinase and nuclear factor-kappaB pathway in retinal pigment epithelial cells. Exp Eye Res 85: 667-677, 2007. 
FANG Y, ZHANG Q, TAN J, LI L, AN X, LEI P: Intermittent hypoxia-induced rat pancreatic beta-cell apoptosis and protective effects of antioxidant intervention. Nutr Diabetes 4: e131, 2014.

GAO Z, YU C, LIANG H, WANG X, LIU Y, LI X, JI K, XU H, YANG M, LIU K, QI D, FAN H: Andrographolide derivative CX-10 ameliorates dextran sulphate sodium-induced ulcerative colitis in mice: Involvement of NF-kappaB and MAPK signalling pathways. Int Immunopharmacol 57: 82-90, 2018.

HARDWICK JM, YOULE RJ: SnapShot: BCL-2 proteins. Cell 138: 404, 404.e1, 2009.

KANG HH, KIM IK, LEE HI, JOO H, LIM JU, LEE J, LEE SH, MOON HS: Chronic intermittent hypoxia induces liver fibrosis in mice with diet-induced obesity via TLR4/MyD88/MAPK/NF-kB signaling pathways. Biochem Biophys Res Commun 490: 349-355, 2017.

KHAN SA, NANDURI J, YUAN G, KINSMAN B, KUMAR GK, JOSEPH J, KALYANARAMAN B, PRABHAKAR NR: NADPH oxidase 2 mediates intermittent hypoxia-induced mitochondrial complex I inhibition: relevance to blood pressure changes in rats. Antioxid Redox Signal 14: 533-542, 2011.

KOLYADA AY, SAVIKOVSKY N, MADIAS NE: Transcriptional regulation of the human iNOS gene in vascularsmooth-muscle cells and macrophages: evidence for tissue specificity. Biochem Biophys Res Commun 220: 600-605, 1996.

KUMAR S, BOEHM J, LEE JC: p38 MAP kinases: key signalling molecules as therapeutic targets for inflammatory diseases. Nat Rev Drug Discov 2: 717-726, 2003.

LEE E, RYU GR, KO SH, AHN YB, YOON KH, HA H, SONG KH: Antioxidant treatment may protect pancreatic beta cells through the attenuation of islet fibrosis in an animal model of type 2 diabetes. Biochem Biophys Res Commun 414: 397-402, 2011.

LIU S, SUN JY, REN LP, CHEN K, XU B: Propofol attenuates intermittent hypoxia induced up-regulation of proinflammatory cytokines in microglia through inhibiting the activation of NF-Bkappa/p38 MAPK signalling. Folia Neuropathol 55: 124-131, 2017.

MARCINIAK A, WALCZYNA B, RAJTAR G, MARCINIAK S, WOJTAK A, LASIECKA K: Tempol, a membranepermeable radical scavenger, exhibits anti-inflammatory and cardioprotective effects in the cerulein-induced pancreatitis rat model. Oxid Med Cell Longev 2016: 4139851, 2016.

NAGAYOSHI M, PUNJABI NM, SELVIN E, PANKOW JS, SHAHAR E, ISO H, FOLSOM AR, LUTSEY PL: Obstructive sleep apnea and incident type 2 diabetes. Sleep Med 25: 156-161, 2016.

PUNJABI NM: The epidemiology of adult obstructive sleep apnea. Proc Am Thorac Soc 5: 136-143, 2008.

RAMOND A, GODIN-RIBUOT D, RIBUOT C, TOTOSON P, KORITCHNEVA I, CACHOT S, LEVY P, JOYEUXFAURE M: Oxidative stress mediates cardiac infarction aggravation induced by intermittent hypoxia. Fundam Clin Pharmacol 27: 252-261, 2013.

SADASIVAM K, PATIAL K, VIJAYAN VK, RAVI K: Anti-oxidant treatment in obstructive sleep apnoea syndrome. Indian J Chest Dis Allied Sci 53: 153-162, 2011.

SKELLY JR, EDGE D, SHORTT CM, JONES JF, BRADFORD A, O'HALLORAN KD: Tempol ameliorates pharyngeal dilator muscle dysfunction in a rodent model of chronic intermittent hypoxia. Am J Respir Cell Mol Biol 46: 139-148, 2012.

SUDBO J, REITH A, FLORENES VA, NESLAND JM, RISTIMAKI A, BRYNE M: COX-2 expression in striated muscle under physiological conditions. Oral Dis 9: 313-316, 2003.

WALIA HK, LI H, RUESCHMAN M, BHATT DL, PATEL SR, QUAN SF, GOTTLIEB DJ, PUNJABI NM, REDLINE S, MEHRA R: Association of severe obstructive sleep apnea and elevated blood pressure despite antihypertensive medication use. J Clin Sleep Med 10: 835-843, 2014.

WANG N, KHAN SA, PRABHAKAR NR, NANDURI J: Impairment of pancreatic beta-cell function by chronic intermittent hypoxia. Exp Physiol 98: 1376-1385, 2013.

WANG Y, HAI B, NIU X, AI L, CAO Y, LI R, LI Y: Chronic intermittent hypoxia disturbs insulin secretion and causes pancreatic injury via the MAPK signaling pathway. Biochem Cell Biol 95: 415-420, 2017.

WILCOX CS: Effects of tempol and redox-cycling nitroxides in models of oxidative stress. Pharmacol Ther 126: 119-145, 2010. 
WU X, GU W, LU H, LIU C, YU B, XU H, TANG Y, LI S, ZHOU J, SHAO C: Soluble receptor for advanced glycation end product ameliorates chronic intermittent hypoxia induced renal injury, inflammation, and apoptosis via P38/JNK signaling pathways. Oxid Med Cell Longev 2016: 1015390, 2016.

XU J, LONG YS, GOZAL D, EPSTEIN PN: Beta-cell death and proliferation after intermittent hypoxia: role of oxidative stress. Free Radic Biol Med 46: 783-790, 2009.

YOKOE T, ALONSO LC, ROMANO LC, ROSA TC, O'DOHERTY RM, GARCIA-OCANA A, MINOGUCHI K, O'DONNELL CP: Intermittent hypoxia reverses the diurnal glucose rhythm and causes pancreatic beta-cell replication in mice. J Physiol 586: 899-911, 2008.

ZHAO YN, WANG HY, LI JM, CHEN BY, XIA G, ZHANG PP, GE YL: Hippocampal mitogen-activated protein kinase activation is associated with intermittent hypoxia in a rat model of obstructive sleep apnea syndrome. Mol Med Rep 13: 137-145, 2016.

ZHENG X, WANG X, MA Z, GUPTA SUNKARI V, BOTUSAN I, TAKEDA T, BJÖRKLUND A, INOUE M, CATRINA SB, BRISMAR K, POELLINGER L, PEREIRA TS: Acute hypoxia induces apoptosis of pancreatic beta-cell by activation of the unfolded protein response and upregulation of CHOP. Cell Death Dis 3: e322, 2012. 